\title{
Risk of Rice Cultivation under Current and Future Environment and Market
}

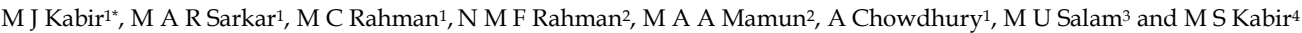

\begin{abstract}
Risk is an inevitable feature of agriculture globally, and it might increase over time in the future. The study assesses the risk of rice cultivation in the three seasons under current and future conditions. The software programme @Risk version 7.6 was used to simulate the risk-return trade of rice cultivation in the three seasons in Bangladesh. The likelihood of having negative net income for the Aus (90\%) and Boro (80\%) rice was very high under the current market and environmental conditions. Besides, the chance of obtaining negative net income was notable for T. Aman (33\%). Both the yield and price variation significantly contributed to the fluctuation of returns of rice production. However, with the current seasonal variation in yield, the probability of having negative net income for paddy rice was very low under the farmers' expected price (Aman: 22.5 BDT kg-1, Boro: 25 BDT $\mathrm{kg}^{-1}$ and Aus: $24 \mathrm{BDT} \mathrm{kg}^{-1}$ ). The result indicates that only access to the fair price of the rough rice can ensure the economic sustainability of the rice production. Likewise, chances of having a negative net income of paddy rice in 2030 will be zero under the extrapolated yield (Aman: $5.3 \mathrm{~kg} \mathrm{ha}^{-1}$, Boro: $6.3 \mathrm{~kg}$

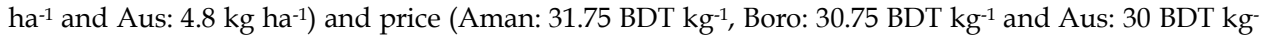
$\left.{ }^{1}\right)$. The findings indicate that rice cultivation in the three seasons will be economically sustainable, subject to achieving the expected genetic gain and ensuring access to the projected price. Thus, policy supports are needed to ensure farmers' access to a fair price, improve management practice, and strengthen research to enhance genetic gain for sustainable rice farming under future conditions.
\end{abstract}

Key words: Production risk, market risk, yield and price fluctuations, economic sustainability.

\section{INTRODUCTION}

Bangladesh is geographically and geomorphologically critically vulnerable to climate change and hot spots of catastrophic natural calamities. It was due mainly to the country located between two distinct environments, particularly the Bay of Bengal in the south and the Himalayas in the north. Besides, greater dependency on agriculture and overpopulation aggravates the susceptibility. Every year the country faces one or more natural calamities in the form of floods, droughts, tropical cyclones, storm surges, and coastal erosion. As a result, concede substantial economic and physical losses as well as a causality of human death (WB, 2013). Table 1 presents the physical vulnerability of different sectors to extreme events, including sea-level rise, floods, droughts and cyclones, and storm surges. It indicates that farming in Bangladesh operates under substantial production risk due to climatic vulnerability. Additionally, seasonal fluctuation in the price of rough rice at farmgate also substantially affected the economic viability of rice cultivation in Bangladesh (Kabir et al., 2017; Kabir et al., 2019).

The risks sometimes jeopardize farm enterprises and force farmers to adapt to the conditions by adjusting their production and management strategies (Hardaker et al., 2004; ADB, 2002; Duong et al., 2019). The risk of T. Aman rice farming was higher for small farmers, followed by medium and large farmers in southwest coastal Bangladesh (Kabir, 2016). Similarly, Aus rice farming was riskier, followed by Boro rice and T. Aman rice (BRRI, 2016). Therefore, evaluation of farm enterprises or technologies solely in terms of average or expected return cannot reflect real scenarios without assessment of risk (Ullah et al., 2016). Besides, the accounting level of risk

\footnotetext{
${ }^{1}$ Agricultural Economics Division, Bangladesh Rice Research Institute (BRRI), Gazipur-1701, Bangladesh; ${ }^{2}$ Agricultural Statistics Division, BRRI, Gazipur-1701, Bangladesh; ${ }^{3}$ Freelance International Consultant (Agricultural Systems), Bangladesh; ${ }^{4}$ Director General, BRRI, Gazipur-1701, Bangladesh.

*Corresponding author's E-mail: jkabirbrri@yahoo.com (M J Kabir)
} 
associated with farming is the key to formulating policies for the sustainability of risky farm decisions (Hardaker et al., 2004; Nastis et al., 2019). Moreover, the information about risk returns trade needs to account for planning at higher levels for the welfare of the farm families (Hardaker et al., 2004; Kabir et al., 2019) as the country has to produce 44.6 MT of rice by 2050 for 215.4 million population of Bangladesh (Kabir et al., 2015). Thus, this study focuses on assessing the risk of rice cultivation in the three rice growing seasons under current and future conditions.

Followed by the introduction, description of methods is presented briefly. It includes choosing a software programme and the assumption of the stochastic budgets to analyze the risk-return trade of Aus, T. Aman, and Boro rice. It presents results and discussions, including major sources of farming risks and their management strategies. This was followed by analyses of the economic viability (profitability and risks) of the Aus, $\mathrm{T}$. Aman, and Boro rice under current and future conditions. Finally, conclusions are outlined.

\section{METHODOLOGY}

In particular, input use pattern, yield, and prices of inputs and outputs of Aus, T. Aman, and Boro rice, farm-level data were collected from 900 key informant rice farmers over the last three years (2017-2019). The data were collected from favourable and unfavourable ecosystems, including salinity, drought, submergence, and haor areas. Stochastic budgets were constructed for representative enterprise budgets to evaluate the riskiness of rice in the Aus, T. Aman, and Boro season. The software programme @RISK Version 7.6 was used along with Excel to derive cumulative density functions (CDFs) of gross margin (GM) and net income (NI) (PC, 2018). Monte Carlo simulation was run following triangular probability distributions of yield and price (Hardaker et al., 2004). It was due to that distribution is best fitted with available data.

The model was run under the following three conditions:

- Farmers perceived seasonal variation in yield and price of Aus, T. Aman, and Boro rice for the last five years (Table 2);

- Farmers observed seasonal variation in rice yield over the last five years and their expected price of Aus, T. Aman and Boro rice (Table 2 ); and,

Table 1. Intensity of impacts on different sectors due to climate change in Bangladesh.

\begin{tabular}{|c|c|c|c|c|c|c|c|c|}
\hline \multirow{3}{*}{$\begin{array}{l}\text { Sectorial } \\
\text { vulnerability context }\end{array}$} & \multicolumn{8}{|c|}{ Physical vulnerability context } \\
\hline & \multirow{2}{*}{ ET } & \multicolumn{2}{|c|}{ Sea level rise } & \multirow[b]{2}{*}{ DT } & \multicolumn{2}{|l|}{ Flood } & \multirow{2}{*}{$\begin{array}{l}\text { Cyclone and } \\
\text { storm surges }\end{array}$} & \multirow{2}{*}{$\begin{array}{l}\text { Erosion and } \\
\text { accretion }\end{array}$} \\
\hline & & $\mathrm{CI}$ & SI & & $\begin{array}{l}\text { River } \\
\text { flood }\end{array}$ & $\begin{array}{l}\text { Flash } \\
\text { flood }\end{array}$ & & \\
\hline $\begin{array}{l}\text { Crop } \\
\text { Agriculture }\end{array}$ & +++ & ++ & +++ & +++ & + & ++ & +++ & - \\
\hline Fisheries & ++ & + & + & ++ & ++ & + & + & - \\
\hline Industries & ++ & +++ & ++ & - & ++ & + & + & - \\
\hline Biodiversity & ++ & +++ & +++ & - & ++ & - & + & - \\
\hline Health & +++ & + & +++ & - & ++ & - & ++ & - \\
\hline Settlement & - & - & - & - & - & - & +++ & +++ \\
\hline Energy & ++ & + & - & - & + & - & + & - \\
\hline
\end{tabular}

Note: ' +++ ' refers to high, '++' refers to moderate, '+' refers to low level of relationship, '-' refers not measure. ET: Extreme temperature, DT: Drought, CI: Coastal inundation, SI: Salinity intrusion. 
- Extrapolated yield (1\% genetic gain per year over existing yield with same seasonal variation and yield gap), price $(6.5 \%$ annual increase as compound growth rate), and cost (15\% increase from baseline cost) in 2030 (Table 2).

Although Monti-Carlo simulation software is highly potential to give precise predictions about risk-return trade-offs. However, the projection of paddy prices under future conditions based on the exponential growth coefficient is not highly reliable.

The best-case yield was obtained under favourable weather conditions and the worstcase yield under unfavourable weather conditions. However, the complete crop loss by extreme events such as floods, cyclones, and storm surges was excluded from the worst seasonal yields. With regards to price, the best price is the price that is obtained in some seasons, and the worst-case price is the price that is obtained in some seasons. The typical seasonal grain yield and paddy prices were the yield and paddy prices obtained in most cases. The highest number of iterations $(10,000)$ was used for simulating each CDF as it increased the stability of the distribution (Lien, 2003). The analysis of risk involved comparing the $\mathrm{CDFs}$ of the alternative cropping options. Simple stochastic dominance rules were applied (Anderson et al., 1988; Dillon and Hardaker, 1993).

Table 2 presents grain yield and price of Aus, T. Aman, and Boro rough rice across three scenarios under historical and 2030 conditions. The current yield was the farmers' observed best, normal, and worst seasonal yield. The current and expected prices were the farmers' observed and expected high, most likely, and low price of rice. Yield in different seasonal conditions was extrapolated by considering $1 \%$ genetic gain per year over existing yield with the same seasonal variation and yield gap. The best seasonal price was extrapolated through accounting for the annual exponential growth of the rough price for the last 22 years.

Table 2. Grain yield and price of Aus, T. Aman, and Boro rough rice in Bangladesh across three scenarios under historical and 2030 conditions.

\begin{tabular}{|c|c|c|c|c|c|}
\hline Season & Parameter & Condition & $\begin{array}{l}\text { Best seasonal/ } \\
\text { high }\end{array}$ & $\begin{array}{l}\text { Typical/ } \\
\text { normal }\end{array}$ & $\begin{array}{l}\text { Worst } \\
\text { seasonal/ } \\
\text { low }\end{array}$ \\
\hline \multirow{5}{*}{ Aus } & \multirow{5}{*}{$\begin{array}{l}\text { Grain yield } \\
\left(\mathrm{t} \mathrm{ha}^{-1}\right) \\
\text { Price } \\
(\text { BDT kg-1) }\end{array}$} & Current & 5.60 & 4.80 & 3.50 \\
\hline & & Extrapolated & 6.20 & 5.30 & 4.10 \\
\hline & & Current & 22.50 & 18.50 & 16.50 \\
\hline & & $\begin{array}{l}\text { Farmers } \\
\text { expected }\end{array}$ & 25.00 & 22.50 & 20.00 \\
\hline & & Extrapolated & 38.25 & 31.75 & 28.25 \\
\hline \multirow{5}{*}{ Aman } & \multirow{5}{*}{$\begin{array}{l}\text { Grain yield } \\
\left(\mathrm{t} \mathrm{ha}^{-1}\right) \\
\text { Price } \\
(\text { BDT kg-1) }\end{array}$} & Current & 6.50 & 5.70 & 4.40 \\
\hline & & Extrapolated & 7.30 & 6.30 & 5.20 \\
\hline & & Current & 23.50 & 18.00 & 15.50 \\
\hline & & $\begin{array}{l}\text { Farmers } \\
\text { expected }\end{array}$ & 27.50 & 25.00 & 22.50 \\
\hline & & Extrapolated & 40.25 & 30.75 & 26.50 \\
\hline \multirow{5}{*}{ Boro } & \multirow{5}{*}{$\begin{array}{l}\text { Grain yield } \\
\left(\mathrm{t} \mathrm{ha}^{-1}\right) \\
\text { Price } \\
(\text { BDT kg-1) }\end{array}$} & Current & 6.50 & 5.70 & 4.40 \\
\hline & & Extrapolated & 7.30 & 6.30 & 5.20 \\
\hline & & Current & 23.50 & 18.00 & 15.50 \\
\hline & & $\begin{array}{l}\text { Farmers } \\
\text { expected }\end{array}$ & 27.50 & 25.00 & 22.50 \\
\hline & & Extrapolated & 40.25 & 30.75 & 26.50 \\
\hline
\end{tabular}

Note: Extrapolated indicates 2030 conditions 


\section{RESULTS AND DISCUSSION}

\section{Risk sources and management strategies}

Risk is an inevitable feature of agriculture both in developed and developing countries as farming operates in uncertain biophysical and economic circumstances (Hardaker et al., 2004; Moschini and Hennessy, 2001). The risk might increase over time under future conditions, including changes in climate and environment, social and economic phenomenon, and trade in agricultural products (Hardaker et al., 2004; ADB, 2002; Duong et al., 2019). The seasonal fluctuations of farm output because of weather variations and price variations, because of the influences of market stakeholders and government policy are the primary sources of risk faced by the farmers (Musser and Patrick, 2002). Figure 1 presents major risks and risk management strategies in farming. The production risk mainly concerns seasonal fluctuations of crop yield due to the unpredictable weather and the incidence of pests and diseases. Besides, the interaction of new technologies, farm characteristics, management practices, the quality of inputs, machinery efficiency, and breeds are also influenced by production risk (Musser and Patrick, 2002; Hardaker et al., 2004; Kabir et al. 2020). The diversification, adoption of biotic and abiotic stress-tolerant cultivars, and pursuing precision agriculture, crop insurance, and contract production are the major production risk management strategies. Contract farming ensured access to favourable prices, insurance protection against loss, and diversification spread the risks (Musser and Patrick, 2002; Hardaker et al., 2004; https://rnrinag. uwagec.org/).

Market risk concerns variations in inputs and outputs prices and quantities of marketable surplus. The changes in government policies (e.g., tariff, levy, and subsidy) or laws, unpredictable global markets for inputs and outputs, exchange rates, and variations in quantities supply due to weather are the drivers of market risk (Musser and Patrick, 2002;
Hardaker et al., 2004; Kabir et al. 2020). Developing a balanced approach or marketing plan based on available information and skills through forwarding, sequential, and contract marketing are major market risk management strategies. Besides, direct sales to consumers and vertical integration might reduce market risk (Musser and Patrick, 2002; Hardaker et al., 2004; https://rnrinag. uwagec.org/).

Risk arises from changes in government rules that have far-reaching implications for farm production, and profitability is institutional or political risk. The major sources of institutional risk include unfavourable policy changes, failure to honor trade agreements by foreign governments, and dealing between business partners and other trading organizations (Hardaker et al., 2004).

Economic viability under three scenarios of yield and price of rice

The economic viability of rice was estimated under three conditions:

- Current conditions indicate farmers' perceived seasonal variation in yield and price of rice over the last five years. The rice yield and price variations indicate the seasonal fluctuation of grain yield and paddy price because of seasonal variation in weather and market.

- Current environmental conditions and farmers expected price- similarly, farmers perceived seasonal variation in paddy yield across the last five years. Besides, farmers' expected price is the price that farmers expect currently to make profitable the rice enterprises.

- Extrapolated yield and price- extrapolated grain yield is the projected yield of rice in 2030 under expected genetic gain and better management. Besides, the extrapolated price is the projected price in 2030 based on the exponential growth rate of paddy prices over the last 18 years. 


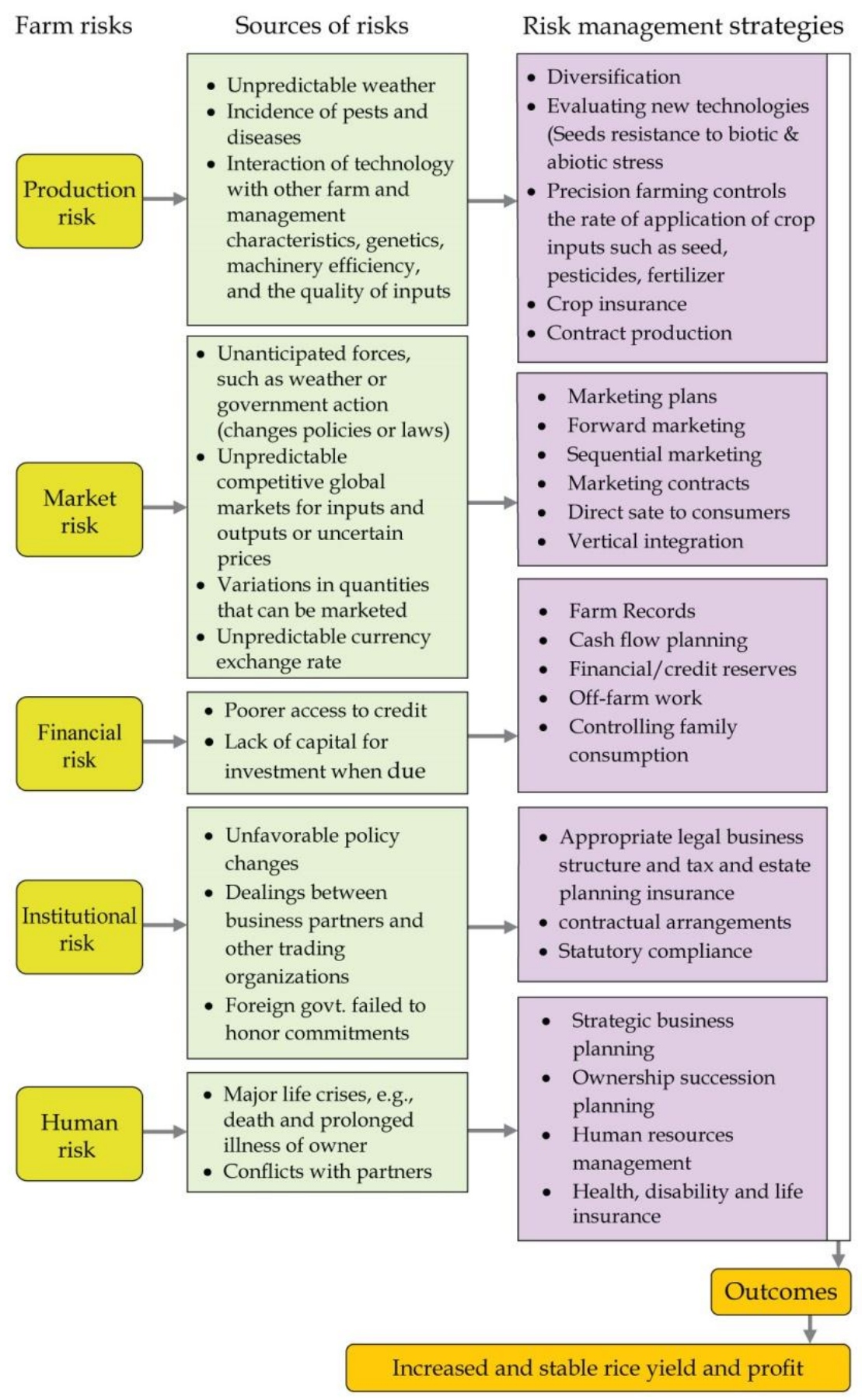

Fig. 1. Major risks and risk management strategies in farming.

Source: Musser and Patrick, 2002; Hardaker et al., 2004; https://rnrinag.uwagec.org/https://rnri nag.uwagec.org/ 


\section{Risk of rice cultivation at current conditions}

Figure 2 presents cumulative probability distribution functions (CDFs) of gross margin per hectare of Aus, T. Aman, and Boro rice at farmers' perceived seasonal variation in yield and price over the last five years.

The probability of having a positive gross margin of T. Aman in the current environment and market conditions was $100 \%$. Under similar conditions, the chances of giving a positive gross margin for Aus was about 98\% and decreased to $97 \%$ for Boro. The risk analysis results indicate that despite the current seasonal price and yield variations, farmers have higher chances of having a positive gross margin from rice irrespective of seasons. The CDF of T. Aman shows firstdegree stochastic dominance over Boro and Aus rice, and the CDF of Boro shows second- degree stochastic dominance over Aus rice, indicating that $\mathrm{T}$. Aman gave a higher gross margin followed by Boro and Aus (Fig. 2).

The sources of variability in the different measures of enterprise returns were analyzed using the @RISK software. In Figure 3, the total variation in gross margin per hectare is partitioned between the sources, namely, the seasonal variation in the yield and price of Aus, T. Aman, and Boro. The variation in the paddy yield contributed most to the gross margin of $\mathrm{T}$. Aman and Aus, followed by fluctuation in price. On the contrary, price variation contributed most to variability in the gross margin of Boro rice, followed by grain yield (Fig. 3). However, the contribution of price in the variability in gross margin of T. Aman and Boro decreased notably (Fig. 4), subject to ensured access to farmers' expected price.

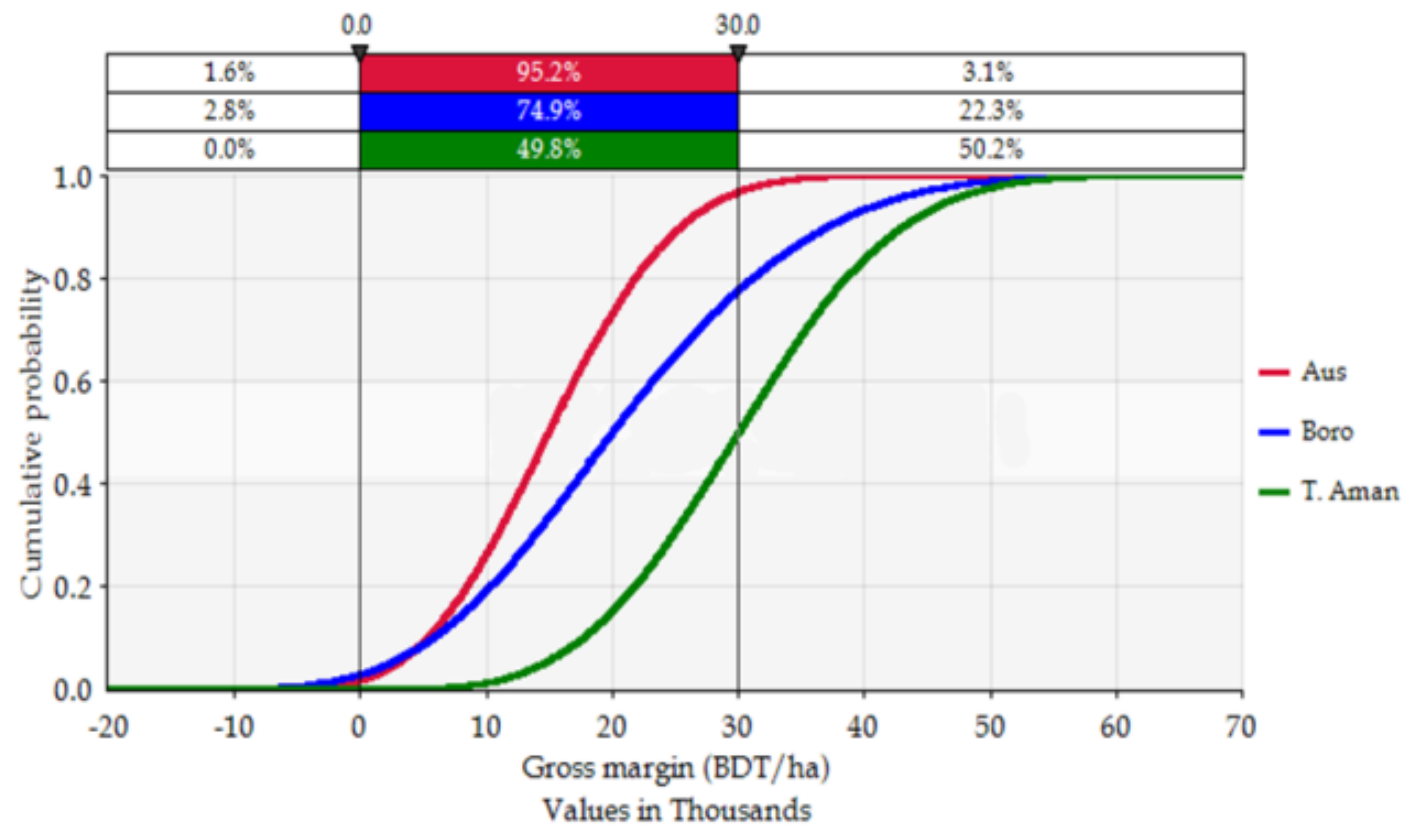

Fig. 2. Cumulative probability distribution of gross margin of Aus, T. Aman, and Boro rice in Bangladesh at farmers' perceived seasonal variation in yield and price. 


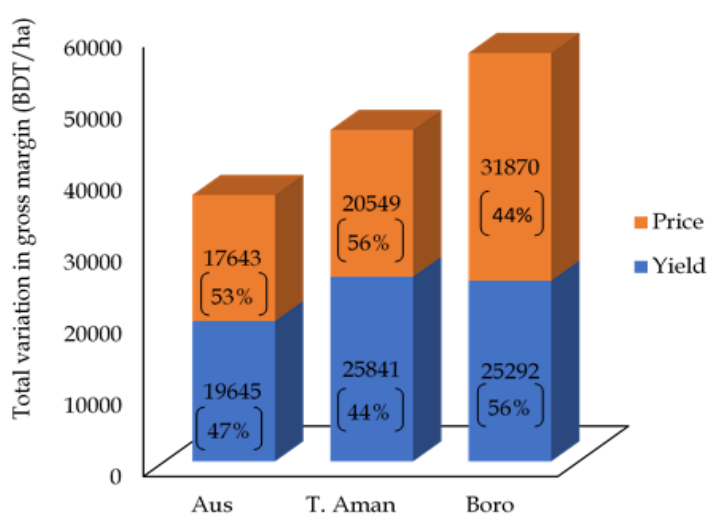

Fig. 3. Inputs ranked by an effect on gross margin per hectare of Aus, T. Aman, and Boro rice in Bangladesh at farmers' perceived seasonal variation in yield and price.

Note: Total variation in gross margin is consists of variation in gross margin due to variation in yield and price; Figures in the bracket indicate percent variation.

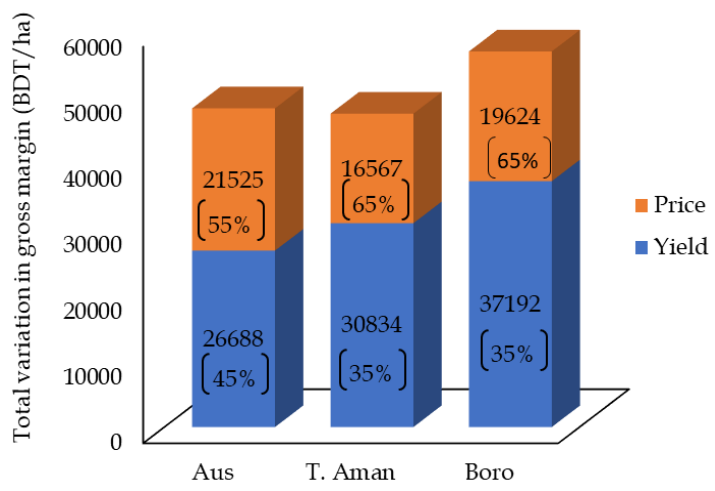

Fig. 4. Inputs ranked by the effect on gross margin per hectare of Aus, T. Aman, and Boro rice in Bangladesh at farmers' perceived seasonal variation in yield and expected price.

Note: Total variation in gross margin is consist of variation in gross margin due to variation in yield and price. Figures in the bracket indicate percent variation.

Figure 5 presents CDFs of net income per hectare of Aus, T. Aman, and Boro rice at farmers' perceived seasonal variation in yield and price. The CDF of T. Aman shows first-degree stochastic dominance over Boro and Aus rice. Besides, the CDF of Boro shows second-degree stochastic dominance over Aus rice. The results indicating that Aus is the most risker, followed by Boro and T. Aman. It can be seen that farmers have over $90 \%$ chance of having total loss from
Aus rice. The probability of total loss decreased to $80 \%$ for Boro rice and 33\% for T. Aman. The risk analysis results indicate that the likelihood of having negative net income for Aus and Boro rice was very high under the current market and environmental conditions. Besides, the risk for $\mathrm{T}$. Aman farming was notable (Fig. 5).

\section{Risk at current environmental conditions and farmers' expected price}

Figure 6 presents CDFs of net income per hectare of Aus, T. Aman, and Boro rice at farmers perceived seasonal variation in yield and expected price. CDFs show that despite seasonal variation in grain yield, the probability of having negative net income from Aus (7\%), Boro (4\%), and Aman (1\%) decreased substantially at farmers' expected price. The key insight of the results of risk analysis is that farmers' ensuring access to fair prices is the cornerstone of the economic sustainability of rice production. It can be noted that farmers expected price is nearly consistent with the government procurement price. Thus, policy supports to ensure farmers' access to government declared price is critically important for sustainable rice production in Bangladesh.

\section{Risk at extrapolated yield and price}

Figure 7 presents the CDFs of net income per ha of Aus, T. Aman, and Boro rice at extrapolated yield, price, and cost in 2030. CDFs show that at extrapolated paddy yield and price, not only the likelihood of having a negative net income of rice was zero, but also the chances of giving net income per hectare over BDT 5,000 even for Aus rice was $100 \%$. The probability of having net income per hectare over BDT 40,000 for Boro and T. Aman was in the range between $99-100 \%$ at extrapolated yield and price in 2030. It was also the case that even the chance of having net income per hectare over BDT 40,000 for Aus rice is about $58 \%$. The results of risk analysis indicate that rice cultivation in the different seasons will be economically sustainable, subject to achieving the extrapolated genetic gain and ensuring access to the projected price in 2030. 


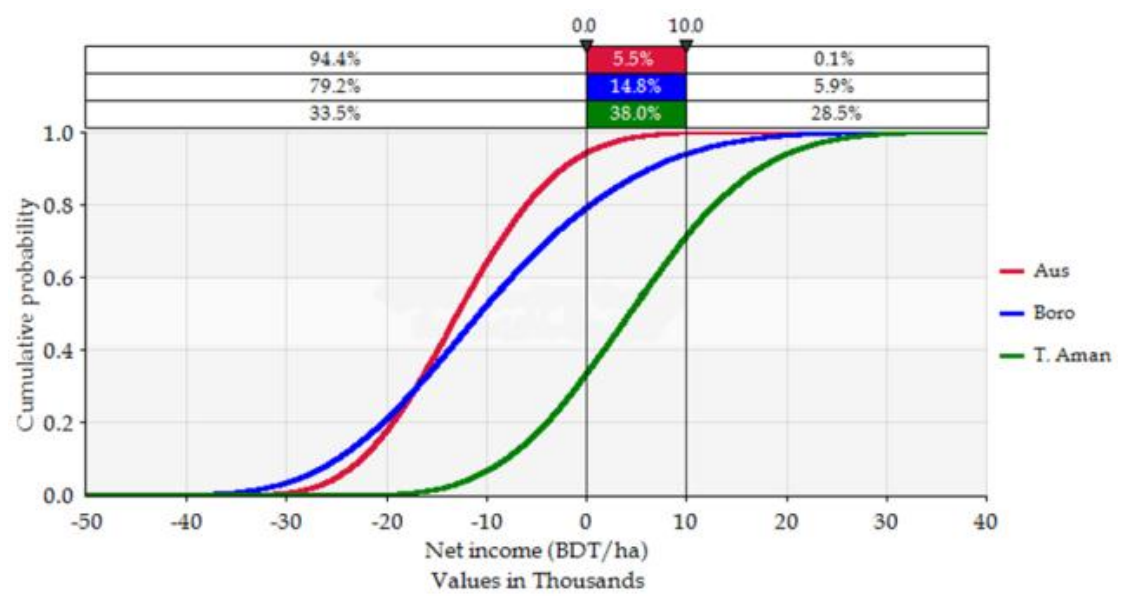

Fig. 5. Cumulative probability distribution of net income of Aus, T. Aman, and Boro rice in Bangladesh at farmers' perceived seasonal variation in yield and price.

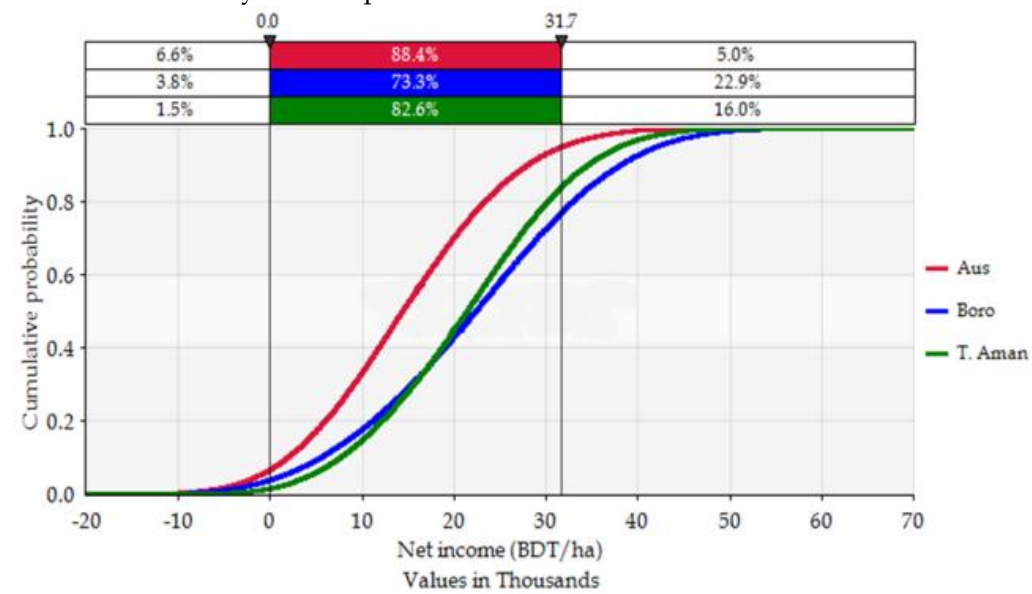

Fig. 6. Cumulative probability distribution of net income of Aus, T. Aman, and Boro rice in Bangladesh at farmers' perceived seasonal variation in yield and their expected price.

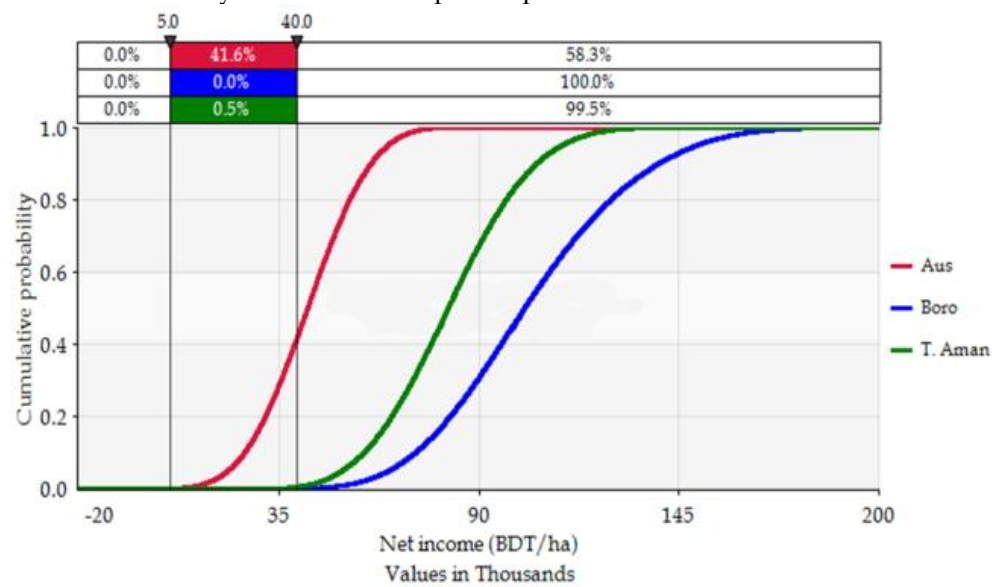

Fig. 7. The cumulative probability distribution of net income of Aus, T. Aman, and Boro rice in Bangladesh at extrapolated yield and price 


\section{CONCLUSION}

The likelihood of having negative net income for the Aus (90\%) and Boro (80\%) rice was very high under the current market and environmental conditions. Besides, the chances of obtaining negative net income were notable for T. Aman (33\%). Both the yield and price variation significantly contributed to the fluctuation of returns of rice production. However, with the current seasonal variation in yield, the probability of having negative net income for rough rice was very low under the farmers' expected price (Aman: 22.5 BDT kg-1, Boro: 25 BDT kg-1, and Aus: 24 BDT kg-1). The finding indicates that only accessing the fair price of the rough rice can ensure the economic sustainability of the rice production. Likewise, chances of having a negative net income of paddy rice in 2030 will be zero under the extrapolated yield (Aman: $5.3 \mathrm{~kg} \mathrm{ha}^{-1}$, Boro: 6.3 $\mathrm{kg} \mathrm{ha}^{-1}$ and Aus: $4.8 \mathrm{~kg} \mathrm{ha}^{-1}$ ) and price (Aman:

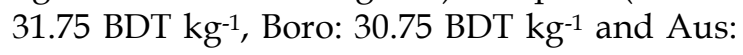
30 BDT kg-1). The finding indicates that only ensuring access to the fair price of the rough rice is vital for the economic sustainability of rice production. Thus, policy supports are required for (i) controlling unscrupulous market deals, (ii) enhancing genetic gain, and (iii) improving management practice for sustainable rice farming under future conditions.

\section{RECOMMENDATIONS}

The following policy recommendations could help ensure a sustainable rice production system in Bangladesh.

- Research should be strengthened for developing higher yield potential stresstolerant rice cultivars to alleviate the adverse consequences of harsher future environmental conditions.

- The extension programmes should be focused on the rapid dissemination of the newly developed higher yield potential cultivars to the end-users in the respective stress ecosystems and a favourable environment.

- The minimum fair price of grain qualitywise rough rice at farm-gate should be declared, and farmers' excess to the price should be ensured to alleviate market risk.

- Farmers' access to soft credit (low-interest rate) should be ensured to improve their adaptive capacity.

- Insurance schemes for rice farming should be commenced protecting farmers from the adverse consequences of extreme weather events (e.g., including droughts, floods, and cyclones).

\section{ACKNOWLEDGEMENTS}

The authors wish to thank anonymous reviewers for their suggestions, which significantly improved this article.

\section{AUTHORS' CONTRIBUTION}

MJK and MARS generated idea; MUS and MSK coordinated the research; MJK developed methodology; MJK, MARS, and MCR provided scientific insights; MJK, NMFR, MAAM, and AC gathered data, carried out analysis and synthesis; MJK did the writings for all versions of the manuscript; MUS, MARS, MCR, and NMFR performed critical review and editing; All authors read and approved the final manuscript.

\section{DECLARATION OF INTERESTS}

A version of the paper was published in the book 'Doubling Rice Productivity in Bangladesh' in 2020 by the Bangladesh Rice Research Institute (BRRI), Gazipur 1701, Bangladesh, to commemorate BRRI's 50 th anniversary. The Bangladesh Rice Journal has prior knowledge of the book publication and does not see any conflict of interest. 


\section{REFERENCES}

ADB (Asian Development Bank). 2002. Handbook for Integrating Risk Analysis in the Economic Analysis of Projects. Asian Development Bank (ADB), Manila, Philippines.

Anderson, J R, J L Dillon and J B Hardaker. 1988. Agricultural Decision Analysis (Third ed.), Iowa State University Press, Iowa, USA.

BRRI (Bangladesh Rice Research Institute). 2016. Estimation of cost and return of MV rice cultivation at farm level. BRRI Annual report 2016-2017, Bangladesh Rice Research Institute, Gazipur-1701, Bangladesh.

Dillon, J L and J B Hardaker. 1993. Farm Management Research for Small Farmer Development (Vol. 6). Rome, Italy: Food and Agriculture Organization of the United Nations (FAO).

Duong, T, T Brewer, J Luck and K Zander. 2019. A global review of farmers' perceptions of agricultural risks and risk management strategies. Agriculture, 9(1): 10.

Hardaker, J B, R B M Huirne, J R Anderson and G Lien. 2004. Coping with risk in agriculture. CAB International, Wallingford, UK.

Kabir, M J. 2016. The Sustainability of Rice-Based Cropping Systems in Coastal Bangladesh: Bio-Economic Analysis of Current and Future Climate Scenarios. PhD thesis. The University of Queensland (UQ), Australia. https://core.ac.uk/download/pdf/83964587.pdf.

Kabir, M J, R Cramb, M Alauddin and D S Gaydon. 2019. Farmers' perceptions and management of risk in rice-based farming systems of southwest coastal Bangladesh. Land Use Policy, 86: 177-188.

Kabir, M S, M U Salam, A K M S Islam, M A R Sarkar, M A A Mamun, M C Rahman, B Nessa, M J Kabir, H B Shozib, M B Hossain, A Chowdhury, M Nasim, K M Iftekharuddaula, M S Hossain, M K A Bhuiyan, B Karmakar, M S Rahman, M M Haque, M T Khatun, M P Ali, S M H A Rabbi, P L Biswas, E S M H Rashid and N M F Rahman. 2020. Doubling rice productivity in Bangladesh: A way to achieving
SDG 2 and moving forward. Bangladesh Rice Journal, 24 (2): 1-47.

Kabir, M J, M Alauddin and S Crimp. 2017. Farm-level adaptation to climate change in Western Bangladesh: An analysis of adaptation dynamics, profitability and risks. Land use policy, 64: 212-224.

Kabir, M S, M U Salam, A Chowdhury, N M F Rahman, K M Iftekharuddaula, M S Rahman, M H Rashid, S S Dipti, A Islam, M A Latif and A K M S Islam. 2015. Rice vision for Bangladesh: 2050 and beyond. Bangladesh Rice Journal, 19 (2): 1-18.

Lien, G. 2003. Assisting whole-farm decision-making through stochastic budgeting. Agricultural Systems, 76 (2): 399-413.

MoEF (Ministry of Environment and Forest). 2005. National Adaptation Programme of Action (NAPA), Final Report, Ministry of Environment and Forest (MoEF), Government of the People's Republic of Bangladesh, Dhaka, Bangladesh.

Moschini, G and D A Hennessy. 2001. Uncertainty, risk aversion, and risk management for agricultural producers. Handbook of Agricultural Economics, 1: 87153.

Musser, W N and G F Patrick. 2002. How much does risk really matter to farmers? In: A comprehensive assessment of the role of risk in US agriculture (pp. 537-556). Springer, Boston, MA.

Nastis, S A, K Mattas and G Baourakis. 2019. Understanding Farmers' Behavior towards Sustainable Practices and Their Perceptions of Risk. Sustainability, 11 (5): 1303.

PC (Palisade Corporation). 2018. The Decision Tools Suite Version 7.6, Palisade Corporation (PC). Available at: https://www.palisade.com/support/manuals.asp.

Ullah, R, G P Shivakoti, F Zulfiqar and M A Kamran. 2016. Farm risks and uncertainties: Sources, impacts and management. Outlook on Agriculture, 45 (3): 199-205.

WB (World Bank). 2013. Turn down the heat: climate extremes, regional impacts, and the case for resilience, 1464800561, The World Bank (WB), Washington, DC, USA. 